\title{
Research on the Construction and Diffusion of Central Plain Culture Under "the Belt and Road" Initiative
}

\author{
Donghai Jin \\ School of Marxism \\ Wuhan University of Technology \\ Wuhan, China
}

\begin{abstract}
The Belt and Road" initiative refers to a comprehensive and innovative development strategy that is proposed by the General Secretary Xi Jinping and has global view and manifests the wisdom of China. It can be regarded as a new try at present to revitalize Chinese culture. As the origin of the ancient "Silk Road" and the crucial node of "the Belt and Road" construction, Henan Province should proactively integrate in the layout of the development strategy. By virtue of the excellent traditional culture that has a long history and profound foundation, Henan Province should create the "Innovation Demonstration Area of Chinese History and Civilization" and regard the people-to-people exchanges and cooperation as the key task of boosting "the Belt and Road" construction. Meanwhile, Henan Province can improve the soft power of Central Plain Culture via various ways, provide cultural support to "make the Central Plains more outstanding", laying a foundation for the Central Plain Culture to go out of Henan Province and go to the world.
\end{abstract}

Keywords-“The Belt and Road"; central plain culture; construction; diffusion

\section{INTRODUCTION}

"The Belt and Road" refers to "the Silk Road Economic Belt" and "the 21st Century Maritime Silk Road". With the global view and manifesting the wisdom of China, it is a comprehensive and innovative development strategy proposed by the General Secretary Xi Jinping. Compared with economic growth, cultural exchange and civilization blending have become the "soft power". In the process of facilitating the economic and trade contact and cultural exchange among countries along "the Belt and Road", how to further improve and manifest the soft power of Chinese culture has become an important measure to reshape the great power of oriental culture and reappear the world civilization map under the global vision in the new era. "The Belt and Road" initiative proposed by the General Secretary Xi Jinping can be regarded as a new try at present to revitalize Chinese culture in the $21 \mathrm{st}$ century. After more than 30 years of the reform and opening up, in the process of proactively promoting the communication of civilization between China and the outside world, Chinese government has established the communication mode of mutual respect, inclusiveness and openness, mutual benefit and win-win cooperation and spread the values of "peaceful emergence", "harmony is precious", "harmony in diversity" and "great harmony in the world" to the world. Widely different from the way of west great powers in plundering via military force and colony, Chinese government has founded a new pattern of cultural identity and then rebuilt new system for human civilization.

As the start of the ancient "Silk Road" and the province along the construction of "the Belt and Road", Henan Province should actively integrate in the layout of the development strategy. When investigating in Henan Province, General Secretary Xi Jinping clearly instructs "Henan Province should build the logistics channel hub that connects Henan Province and the outside world and radiates the east, the central and the west to make contributions for the construction of the Silk Road Economic Belt", "the realization of "two centenary" goals and the Chinese Dream of the great rejuvenation of Chinese nation requires the more outstanding Central Plains". It has pointed out the direction for Henan Province to participate in the construction of "the Belt and Road" and accelerate the rising of the Central Plains. In November 2015, Henan Province has formulated the Implementation Plan of Henan Province in Participating in the Silk Road Economic Belt and the 21st Century Maritime Silk Road and taken the people-to-people exchanges and cooperation as one of the crucial tasks of promoting the construction of "the Belt and Road", in order to create the "Innovation Demonstration Area of Chinese History and Civilization Inheritance" and provide cultural support for "more outstanding central plains" on the basis of the excellent traditional culture with a long history and profound foundation. Therefore, under the background of "the Belt and Road" initiative, better constructing and spreading the culture of central plains and improving the soft power of the Central Plain Culture has been endowed a profound connotation of the times. How to integrate the construction and diffusion of the Central Plain Culture in "the Belt and Road" initiative, improving the soft power of the Central Plain Culture via multiple ways to achieve the accept of more people has become the important measures to construct and spread the Central Plain Culture under the global view in the new era. 


\section{THE BACKGROUND OF CONSTRUCTION AND DIFFUSION} OF THE CENTRAL Plain CUlture UNDER THE NEW SituATION

In 2017 , the strategic guideline of constructing a powerful cultural country of socialism was proposed in the report of the 19th National Congress of the Communist Party of China, implementing the "improvement of the national cultural soft power" in "building well-off society in an all-around way and realizing the great rejuvenation of the Chinese nation". Constructing a powerful cultural country of socialism and giving play to the soft power of Chinese culture should make a difference in the great strategy of "the Belt and Road", fully making culture play the role of bridge. When adhering to the values of harmony in diversity and conforming to the current world trend of diversified human civilization, China should conduct cultural exchanges and cooperation with countries along "the Belt and Road". China and other countries involved in "the Belt and Road" should learn from each other and strengthen mutual trust. At the meantime, when actively promoting the "going out" of Chinese culture, China must spread the values of Chinese culture that manifest Chinese spirit and expand the international influence. China should actively shape the image of Chinese government via cultural exchanges, strengthen the speaking right of China on the world stage. The international platform of "the Belt and Road" will arouse the Chinese culture left on the ancient "Silk Road" and lay a solid foundation for Chinese culture to become renowned in the world and dominant among the world cultures.

As the important headstream of Chinese nation and Chinese civilization, Henan Province should become a powerful cultural province on the basis of inheriting the traditional Central Plain Culture. In November 2011, the construction of Central Plain Economic Zone has turned into a national strategy. It is explicit that the construction of innovation area of Chinese history and civilization is taken as one of the five strategic positioning of the Central Plain Economic Zone. Because Henan Province is the origin of the ancient "Silk Road" and becomes the node of "the Belt and Road" initiative, the construction and diffusion of Central Plain Culture usher in new opportunities, which provide ceaseless power for the development of the Central Plain Economic Zone and lay solid ideological and cultural resources for the rise of Central Plains.

\section{AdVANTAGES OF THE HistoricAl ACCUMULATION OF Central Plain Culture}

In July 1, 2016, in the speech to celebrate 95th anniversary of the founding of the Communist Party of China, the General Secretary Xi Jinping proposed, "The cultural confidence is a more fundamental, extensive and profound confidence." "China has the solid road confidence, theory confidence and system confidence, the nature of which is the cultural confidence that is established on the spread of civilization of over 5,000 years." Why the cultural confidence is highlighted by the General Secretary Xi Jinping? "Civilization especially ideology and culture is the spirit of a country and a nation. A country and a nation will not develop if it fails to cherish ideology and culture, namely the spirit." In the modern world, all the nations and countries in the community have the core of their civilization, because it is the basic value to maintain and guard the same community. Therefore, we must revitalize the intrinsic reasonable values of China to revitalize Chinese civilization. Just as the General Secretary $\mathrm{Xi}$ Jinping emphasizes, "The excellent traditional culture is the fundamental for the inheritance and development of a country and a nation. Abandoning it means cutting off the spirit lifeblood." "The excellent traditional Chinese culture is the prominent advantage of the Chinese nation. The great rejuvenation of the Chinese nation requires the development and prosperity of Chinese culture. We must enormously carry forward the excellent traditional Chinese culture." At the same time, he addresses we must treat the traditional culture with a scientific attitude, "We can open up the future only by not forgetting the origin, and we can better innovate only by being adept in inheritance." ${ }^{[1]}$ Meanwhile, he emphasizes in the new era, we must realize the creative transformation and innovative development of the traditional culture and make it blend with the realistic culture. "The traditional Chinese culture is the 'root' and 'spirit' of our nation. Abandoning the tradition and root means cutting off our spirit lifeblood. We must stick to the methods of Marxism, take the attitudes of Marxism and make the past serve the present, get rid of the stale and bring forth the fresh. We must treat them after identification and inherit after removing the dross. That is to say, we must neither onesidedly esteem the past over the present nor emphasize the new and deemphasize the old". "We should deeply excavate and explicate the value of the excellent Chinese culture in stating kindheartedness, emphasizing the sovereignty of the people, keeping integrity, advocating justice and harmony and seeking the great harmony." In addition, we must carry out the creative transformation and innovative development of the traditional culture. New times connotation and modern expression form must be given to the excellent traditional culture to activate its vitality. Its connotation must be supplemented, expanded and improved, in order to enhance its influence and emotional appeal. Only by rooting in the traditional Chinese culture and continuing the blood linkage of national culture can we provide a profound ideological resources and theoretical support for the construction of a powerful cultural country of socialism. The inheritance of the excellent traditional culture does not means being complacent and conservative. On the contrary, we must absorb the outstanding civilization achievements and choose and follow what is right. Civilization becomes colorful because of communication and becomes rich because of exchange. The spirit of speech given by the General Secretary Xi Jinping about constructing the powerful cultural country of socialism has provided a theoretical guidance for the construction and diffusion of Central Plain Culture under the background of "the Belt and Road" initiative.

With abundant resources and historical accumulation, the Central Plain Culture has nourished the brilliant and gorgeous Chinese civilization. The Central Plain Culture is also the important headstream of Chinese culture and has become the core of Chinese civilization. Just as some reviewers comment, "The traditional Central Plain Culture is the important foundation and maternal culture of Chinese culture", and it is of long standing. Advantaged historical and cultural resources such as Emperor Alliance Meeting, Oracle Bones from Yin Ruins, Shang City Ruins, Shaolin Temple, Longmen Grottoes, Songyang Academy, Riverside Scene at Qingming Festival, 
Neixiang Local Magistrate's Office have been left since ancient times. Henan Province has four ancient capitals among the eight ancient capitals of China, namely Luoyang city, which is famous as the imperial capital of thirteen dynasties of thousand years of history, Kaifeng and Anyang, which are the ancient capital of seven dynasties and Zhengzhou, the capital of Shang Dynasty. According to the academic research, over 20 dynasties and over 200 emperors in history found capitals or move the capital to Henan Province. As the center of politics, economy and culture of past dynasties, Henan Province has owned the relatively mature system culture. A total of 1,500 ancient and modern last names originate from Henan Province, which is praised as the outdoor "Museum of Chinese History" because of its rich cultural relics and historic sites. The advantages of historical accumulation of Central Plain Culture are evident. In the river of long history, the Central Plain Culture including Yan-Huang Culture, Heluo Culture and Yin-Shang Culture with the unique regional characteristics has been formed.

Since the reform and opening up, the Central Plain Culture has actively adhered to the strategies of "bringing in" and "going out". The construction and diffusion of Central Plain Culture has achieved results. Its influence on the stage of the world's cultural exchange has further expanded. Henan Province has also been a great cultural province in China because of the colorful Central Plain Culture with profound foundation and a long history. To turn from a great cultural province to a powerful cultural province and actively integrate in "the Belt and Road" initiative, the Central Plain Culture should shoulder the historical task of constructing a powerful cultural country. The former premier Wen Jiabao expected in the construction of Central Plain Economic Zone, "Henan Province has the profound cultural deposits...We shall never forget culture when compiling the planning of economic and social development; we should not forget the soft power when we put emphasis on the hard power... we should not forget the improvement of comprehensive quality, social morality and custom when we emphasize development." The construction of Central Plain Economic Zone depends on the support of characteristic soft power of Henan culture. The construction and diffusion of Central Plain Culture must root in the inheritance of Central Plain Culture. Innovation that conforms to the characteristics of the times must be conducted ceaselessly on this basis to construct the "Innovation Demonstration Area of Chinese History and Civilization Inheritance". Only by basing on the advantages of the traditional Central Plain Culture and carrying out construction and innovation can we spread the rich historical and cultural resources to the whole world, so that people throughout the world will understand the history of Chinese civilization that is continuous and has a long history of five thousand years through understanding the Central Plain Culture. Therefore, we will improve the soft power, influence and emissive power of Central Plain Culture and make contributions to the revitalization of Chinese national culture.

If we say the spirit of openness, inclusiveness, freedom and harmony opened by the ancient "Silk Road" has immensely promoted the economic development and cultural prosperity of continents of Europe and Asia and improved the exchange of human civilization, then we can say the current "the Belt and Road" initiative has inherited the spirit of ancient "Silk Road" at the same time established new economic corridor and covered new channels of cultural exchange at all levels such as language, idea, art and education. "Peace and cooperation, openness and inclusiveness, mutual learning and mutual benefit and win-win result" has become the common purpose that runs through the ancient and the present. Seeking common development and creating the community of shared interests and the community with a common future with cultural inclusiveness has become the theme of "the Belt and Road" in the new period. The diffusion of Central Plain Culture should depend on the great strategy of "the Belt and Road" proposed by the Chinese government. We should proactively give play to the role of cultural exchange and cooperation and continuously expand the emissive power, influence and emotional appeal of Central Plain Culture and make contributions to improve the soft power of Chinese culture.

\section{DILEMMA FACED BY THE CONSTRUCTION AND DifFusion of CENTRAL Plain CUlTuRE}

Ample and profound historical and cultural resources have been left in the Central Plain Culture after thousand years of development. However, the protection, development and utilization of cultural resources have been laggard for many reasons. In terms of the popularity, big gap exists between other powerful cultural provinces and Henan Province. The vitality and influence of the ample cultural resources can be manifested only through unceasing development, excavation and innovation and revealing its internal historical and cultural connotation. The weak development has restricted the improvement of the popularity of Central Plain Culture and been the main barrier of the construction and diffusion of Central Plain Culture and the improvement of cultural soft power. Since the "Inheritance Area of Chinese Historical Civilization" becomes one of the five strategic positioning of Central Plain Economic Zone in 2011, Henan Province has actively deployed, intensified the construction of Central Plain Culture and expanded the channels for the "going out" of Central Plain Culture. For example, people have depended on resources of ethnic origin culture and established a series of cultural platforms like ancestor worship grand ceremony in hometown of the Yellow Emperor, cultural festival of Chinese family name, which have attracted Chinese people at home and abroad to get together in the Central Plain and have a tremendous influence in the world. In the form of exquisite art that combines idea and art, it has formed the large Yu Opera in ancient costumes like Cheng Ying Saved the Orphan, Eternal Regret of Guo State, the large live-action performance like Zen Shaolin Music Ceremony, Song Dynasty Dongjing Dream, the large musical drama Dahe Show, Gorgeous Henan. The literary works have provided colorful spiritual and cultural products for people in the Central Plain even all over China. Besides, the historical and cultural resources in the Central Plain are shown in the literary forms that are popular among the masses. It has not only excavated the excellent historical and cultural resources in the Central Plain but also let people feel the charm of the Central Plain Culture, attracting the attention of people at home and abroad. At present, the construction and diffusion of the Central Plain Culture has 
achieved initial success, but Henan Province fails to make the most of cultural resources. It is in urgent need of strengthening the awareness of innovative development.

\section{A. It Lacks the Integration of Historical and Cultural Resources and Shows the Large but Not Perfect, Scattered but Not Agglomerate Pattern}

In the history of five thousand years, the Central Plain Culture is of long standing and has left ample historical and cultural resources. The headstreams of dragon culture, family name culture, farming culture and Chinese character culture as well as the headstreams of Confucianism, Taoism and Buddhism exist in the Central Plain. The investigation has unveiled there are more than 70,000 valuable and immovable historical relics in Henan Province. ${ }^{[2]}$ The volume of underground cultural relics and cultural relics in the collection of cultural institution in Henan Province ranks first in China. ${ }^{[3]}$ Henan Province has also been praised as the outdoor "Museum of Chinese History" because of its rich cultural treasures and historic sites. The idea that "our origin exists in the Central Plain" has been generally accepted. The historical and cultural heritages of Henan Province rank top in China, which has fully shown the profound historical and cultural resources in Central Plain. Having possessed the profound historical and cultural resources, Henan Province fails to realize full development and excavation. More than 5,700 cultural figures that are influential in dynastic histories from remote antiquity till the Ming Dynasty have not been deeply researched, let alone the cultural effects throughout China. For example, the Du Fu's Thatched Cottage in Chengdu is renowned, but $\mathrm{Du} F$ 's Hometown in Gongyi City of Henan Province is left without anybody to care for it; the story that the pilgrim of Monk Tang Xuanzang retrieving the sutras is famous in China, but how many people know the hometown of the Xuanzang, namely Yanshi City of Henan Province? Compared with Suzhou Gardens and Summer Palace, the five world cultural heritage sites in Henan Province (Longmen Grottoes, Anyang Yin Ruins, the historical and cultural building groups "In the World" in Dengfeng, Henan Section of the Silk Road "One City, One Gate, One Pass and One Road", and Henan Section of the Grand Canal) have more connotation and superior historical origins, but weaker fame and influence. Except for Longmen Grottoes, White Horse Temple, Shaolin Temple and Xiangguo Temple that are famous in China, Songyang Academy, Terrace to King Yu the Great and Mausoleum of Emperors of Song Dynasty are only famous at county and municipal level. Such examples are too numerous to mention one by one.

To highlight the vitality of colorful historical and cultural resources in the Central Plain, we need to develop and excavate and reveal its historical connotation, so that we can make more contributions to the construction and diffusion of the Central Plain Culture. At present, the weak development has become the barrier and bottleneck that restrict the construction and diffusion of the Central Plain Culture. The primary causes are as follows: Firstly, the Central Plain Economic Zone and Zhengzhou Airport Economy Zone are at the initial stage, and Henan Province invests less in the development and excavation of cultural resources. Secondly, excavation of the connotation of historical and cultural resources exists, but they largely rest on the level of academic research and fail to make a difference among the masses, let alone having effects at home and abroad. Thirdly, people involved are shortsighted and regard economic profit as the only purpose. The utilitarian method and the absence of overall consciousness and long-term strategic insight have become the important reasons that influence the improvement of the construction and diffusion of the Central Plain Culture.

\section{B. The Innovation Consciousness of Cultural Brands Is Weak, and the Development Potential Is Insufficient}

The promotion of the construction and diffusion of the Central Plain Culture must depend on the advantages of cultural brands. Establishing the brand effect can guide people to understand the cultural resources in the Central Plain. With these brands, the construction and diffusion of the Central Plain Culture is further highlighted in the great strategy of "the Belt and Road". Because of the insufficient development and excavation, the historical connotation of cultural resources in the Central Plain has not manifested completely, which has restricted the formation of cultural brands that have international influence. It fails to meet the requirements of the State Council for Henan Province to cultivate "cultural brands that have the styles of Central Plain, Chinese characteristics, characteristics of the times and international influence" in the Innovation Area of Chinese History and Civilization Inheritance. At present, representatives of cultural brands of Henan Province include exquisite cultural scenic areas like Longmen Grottoes and Shaolin Temple, the live-action drama Zen Shaolin Music Ceremony, Song Dynasty Dongjing Dream, and TV programs of Li Yuan Chun and Wu Lin Feng, as well as acrobatics in Puyang, magic in Baofeng, Majie Costume Assembly and wood block in Zhuxian Town. Shaolin Temple has formed cultural brand effect internationally, but in recent years, Shi Yongxin, the abbot of Shaolin Temple, covers Shaolin Temple with utilitarian and secular colors. Besides, the public and the media have doubted him, further weakening the connotation of the sacred Buddhist culture in Shaolin Temple, so that its good name at home and abroad is damaged. Li Yuan Chun is an exquisite TV program with regional features created by Henan Province and influential among traditional Chinese opera program. However, compared with the most popular entertainment programs in China, it has more audiences of middle and old ages and has little influence among the young. Compared with powerful cultural provinces and western developed countries, it has few cultural brands and weak innovation and is ill-matched with the position of large province with historical and cultural resources. Of course, the transformation from cultural resources in the Central Plain with profound history to cultural brands is never accomplished in an action but needs long term planning. We must abandon the outdated idea that only pursues economic benefit and excavate historical connotation and ideological connotation, in order to finally form market-oriented cultural brands with a strong emissive power.

\section{The Diffusion Mode Is Excessively Single and Needs to Be Intensified}

The construction and diffusion of the Central Plain Culture benefits the contemporary and is an ever-lasting achievement, requiring long-term planning and cooperation of many sides. It 
needs the support of the government as well as the public; the force of the traditional media is far from enough. The popular internet and new media are also needed to jointly diffuse the Central Plain Culture in many channels and dimensions. Existing influential cultural activities such as "the Ancestor Worship Grand Ceremony in Hometown of the Yellow Emperor" in Xinzheng City, "International Shaolin Martial Arts Festival", "Peony Cultural Festival in Luoyang of China", "Cultural Festival about Yin Ruins of Anyang", and "Chrysanthemum Festival of Kaifeng in China" are dominant by the government. Few of them are held by the common people. They have not cooperated with mainstream media communication platforms at abroad and local media in Henan Province also fail to play the dominant role. The diffusion of the Central Plain Culture mainly depends on the traditional media. Network media and new media fail to vigorously spread the Central Plain Culture. The inadequate diffusion severely has influenced its influence. Therefore, people at home and abroad know few about the profound cultural resources in the Central Plain. The research on the historical and cultural figures in Henan Province is at the initial stage. They are not famous among the public, let alone having influence in China even the whole world. Characteristic regional cultures in the Central Plain Culture have played an important role in the world, but most of them are limited to the academic circle, and few are known to the outside world. The absence of diffusion channels of multiple dimensions and perspectives has made the diffusion of the Central Plain Culture become single and is also the main reason for its insufficient influence at home and abroad.

\section{COUNTERMEASURES TO INTEGRATE THE}

CONSTRUCTION AND DIFFUSION OF THE CENTRAL PLAIN

CULTURE IN “THE BELT AND ROAD” INITIATIVE

\section{A. Under the Guidance of the Socialist Core Values, We Should Excavate the Historical Connotation of the Cultural Resources in the Central Plain at Multiple Levels and Perspectives and Intensify the Integration to Manifest the Charm of the Cultural Resources in the Central Plain and Enhance Its Popularity and Influence}

It is necessary to research historical and cultural resources to present its cultural and artistic values and enhance its popularity to let more people understand the charm of the Central Plain Culture and understand the core status of the Central Plain Culture in the historical and cultural development of Chinese nation. When excavating historical and cultural resources, we should clearly convey the core values contained in the cultural resources at the meantime express in the ways popular among the public. At the same time, we must spread the Central Plain Culture, focus on promoting the construction of the diffusion system of the Central Plain Culture and create the statement of new concepts and categories that are renowned at home and abroad to perfectly tell stories of the Central Plain and spread the voice of the Central Plain. For example, the hometown of Xuanzang is located in the Central Plain. We can make use of the history that is famous around the world, "Tang Monk's Pilgrimage for Buddhist Scriptures" and turn it into an important point for the Central Plain Culture to integrate in "the Belt and Road" initiative, in order to provide support for the cultural exchange between the Central Plain in China and countries along "the Belt and Road".

\section{B. We Can Combine the Construction and Diffusion of the Central Plain Culture with Tourism to Form the Benign and Interactive Development Layout and Expand the Influence of Cultural Resources in the Central Plain}

In this way, tourist attractions can manifest popularity and connotation by virtue of historical and cultural resources, at the same time, the diffusion of historical and cultural resources will be intensified with tourism as the carrier. As a province with numerous cultural resources, Henan should combine culture with tourism, which will fuel economic growth and popularize and manifest the charm of the Central Plain Culture and improve the influence of cultural resources in the Central Plain throughout the world. In the development and excavation of cultural heritages, we should seek meaningful models that convey the spirit of the Central Plain Culture, establish symbolic architectures of cultural landscapes and cultural heritage conservation areas, in order to completely show cultural heritages of the Central Plain in front of people and manifest the spiritual connotation of the Central Plain Culture. In addition, the government can depend on the advantages of ancient historical and cultural capitals to create famous historical and cultural cities and build tourist attractions located in the ancient capitals that are famous around the world For example, Buddhism has enabled Central China even China and numerous countries involved in "the Belt and Road" to establish deep friendship. We can centralize on the culture of "Shaolin Temple" in Mount Song and spread the spiritual idea of the Central Plain Culture to make the charm of Buddhim shine in the cultural exchanges of "the Belt and Road" and improve the international emissive power and influence of the Central Plain Culture.

\section{We Should Change Thinking and Make the Public Access to the Cultural Construction}

We can make domestic people accept the Central Plain Culture in an amiable way; tell stories about the Central Plain in international language and let people in countries involved in "the Belt and Road" favor the Central Plain Culture. Next, we must realize industry-university-research cooperation and conduct multidimensional planning and diffusion to improve the penetration, popularity and influence of cultural resources in the Central Plain. Except for the government that play a dominant role, we should let all parts of society extensively participate in it for form the new path with the cooperation of government, universities, business and people. Particularly, we must introduce influential "folk artisans" in the Central Plain to the system of cultural diffusion, absorb quintessence in folk culture and make it spread faster in the folk under the help of media platforms. In addition, it is necessary to make the most of new media platforms of network and WeChat to build new pattern of the construction and diffusion of the Central Plain Culture. In terms of the way of cultural diffusion, we must fully create platforms to carry out the exchanges of folk culture with countries involved in "the Belt and Road" and encourage enterprises and social institutions of Henan Province to "perform in opera on the stage" in order to silently spread the Central Plain Culture. For example, films, TV plays, books and periodicals that reflect the Central Plain Culture must have 
international view to spread at abroad. We must understand the characteristics of different audiences for cultural needs and be adept in adopting concepts, categories and statements that are famous around the world and organically combine what we want to say with what foreign people want to listen, more vividly reflecting the real life in the present society, in order to let the world understand and accept the Central Plain Culture and make the Central Plain Culture go out of Henan Province.

\section{To Establish a Perfect Creation and Evaluation System for the Diffusion of the Central Plain Culture}

The perfect creation and evaluation system of cultural diffusion must be established if the Central Plain Culture wants to go out of Henan Province. Henan Province must establish high-level institute for the humanities and social sciences, strategic supply center of the Central Plain Culture, ideological construction center, knowledge communication center, artistic creation center, audience demand center, cultural evaluation center and gather and absorb talents about politics, economy, humanities, history, philosophy, journalism and publishing and interdisciplinary talents with international view, especially application-oriented talents that can systematically integrate Chinese culture with western culture. At the same time, it should build a joint think bank of the development of Central Plain Culture to lay a solid talent foundation for the construction and diffusion of the Central Plain Culture. In addition, the perfect evaluation system of cultural diffusion must be established to evaluate from aspects of core cultural ecology, historical and cultural inheritance, public culture supply, public culture participation, cultural economic output, cultural market development, cultural influence and cultural innovation ability to improve cultural creation via a systematic and all-round evaluation from beginning to end. For example, we can refer to the Index System of World Urban Cultural Development of the United Nations to establish the evaluation system of the construction and diffusion of the Central Plain Culture to comprehensively evaluate the construction of cultural system in Henan Province, improve the influence of Central Plain Culture faster and make the Central Plain Culture go out of Henan Province and go to the world under the background of "the Belt and Road" initiative.

\section{CONCLUSION}

To sum up, "the Belt and Road" is a global strategy that has global view and contains Chinese wisdom and is proposed by the Central Committee of the Communist Party of China lead by Xi Jinping. As the origin of the ancient "Silk Road" and becoming the province along the construction of "the Belt and Road", we must fully depend on the great strategy to make Henan Province become "the logistics channel hub that connects Henan Province and the outside world and radiates the east, the central and the west", create "Innovation Demonstration Area of Chinese History and Civilization Inheritance" and provide cultural support to "make the Central Plains more outstanding". The platform of the great strategy will accelerate the diffusion of the Central Plain Culture and improve its influence and emissive power in the world to let Chinese descendants and people at abroad understand the charm of the Central Plain Culture. Meanwhile, it has improved the cultural soft power of the Central Plain Economic Zone and the cohesion of Chinese culture in the development of "the Belt and Road" as well as provided support for realizing the strategy of building a powerful cultural country.

\section{REFERENCES}

[1] Xi Jinping: Speech at the International Symposium on the 2565th Anniversary of Confucius's Birthday and the Opening Ceremony of the 5 th Congress of the International Confucian Federation, People's Daily, Sept.25, 2014.

[2] Xie Xiaoqin. How Are the Tourism Landscape Manufactured? [J] Chinese Public Administration, 2017(1)

[3] Qu Jingdong. Project Responsibility System: A New National Governance System [J], Social Sciences in China, 2012(5).

[4] Gu Jianquan, Wei Shaosheng. Cultural Development Report of Henan (2012) [R], Beijing: Social Sciences Academic Press, 2012.

[5] America] Written by James, translated by Wang Xiaoyi. National Perspective [M], Beijing: Social Sciences Academic Press, 2011.

[6] Wang Hui. The "Not to Offend" Logic in Rural Governance [J], Journal of South China Agricultural University (Social Science Edition), 2011 (7).

[7] Zheng Xin. Research on the Construction of Rural Culture under the Governance Dilemma: Taking Rural Library as an Example [J], Journal of China University of Geosciences (Social Science Edition), 2012(3).

[8] Liu Xiaochun. Who's Original Ecology? Why Is AuthenticityAnalysis on the Original Ecological Phenomenon under the Context of Intangible Cultural Heritage [J], Academic Research, 2008(2). 